Research Article

\title{
Health Technology Assessment Challenges for Orphan Medicinal Products in Low- and Middle-income Countries in Europe
}

\author{
Anna Mateva ${ }^{1}$, Konstantin Tachkov ${ }^{1}$, Antoniya Yanakieva ${ }^{2}$, Petya Milushewa ${ }^{1}$ \\ ${ }^{1}$ Medical University of Sofia, Faculty of Pharmacy, 2 Dunav Str., Sofia, Bulgaria. \\ ${ }^{2}$ Medical University of Sofia, Faculty of Public health, Bjalo More Str., Sofia, Bulgaria. \\ *Corresponding author's E-mail: petya.milushewa@gmail.com
}

Received: 12-06-2021; Revised: 18-08-2021; Accepted: 26-08-2021; Published on: 15-09-2021.

\begin{abstract}
The purpose of this research is to provide a short overview of the differences in access to and health technology assessment of OMPs in selected low- and middle-income countries in Europe and discuss these in terms of some challenges in the face of HTA comparing with high-income countries. This is a retrospective, desktop study of already published official inquiries of national or international institutions, scientific publications, and reports from national governing bodies who regulate and monitor HTA in low- and middleincome economies in Europe, with further regards to HTA of orphan medicinal products. Among all selected low- and middle-income countries in Europe - Bulgaria, Serbia, North Macedonia, Moldova, Ukraine, and Georgia, have available and up-to-date information regarding their health care legislation. During 2000-2019 EMA approves 164 orphan medicines and out of them from 23 to 133 were found in the selected countries. We found that Bulgaria has a special HTA body. Since 2015 in Ukraine the health care system is experienced dynamic reform. In particular, a legislative framework has been adopted that regulates pharmaceutical pricing and reimbursement policies, the introduction of health technology assessment (HTA), etc. Despite the fact that Serbia is not part of the European Union there is an HTA commission established by the Ministry of Health where members of the HTA committee have 5year mandates. According to our research, Georgia and North Macedonia do not use HTA. Meanwhile, United Kingdom is well known to show a strong interest in evidence health care. system. On the other hand, The Statutory health insurance system (SHI reform), since 2000, established a federally funded HTA program with a database of relevant HTA results. Even though that the high-income countries have more developed HTA guidelines and stronger and more secure health systems, all the countries mentioned in this work are facing similar challenges. All the countries have limited budgets that have to be specifically spent for OMPs. Countries with less-developed HTA should take all the knowledge for good practices from countries like the United Kingdom for a more rigid framework. On the other hand, the adoption of public health plans with support from the World Bank, WHO, and the EU as adopted by Serbia and other comparable countries, represent model examples to be shared in greater depth from all the low-income countries.

Keywords: Rare diseases, Orphan medicinal products, Health Technology Assessment (HTA), low- and middle-income countries, highincome countries.
\end{abstract}

QUICK RESPONSE CODE $\rightarrow$

DOI:

10.47583/ijpsrr.2021.v70i01.008

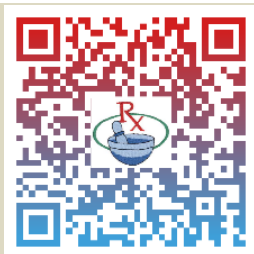

DOI link: http://dx.doi.org/10.47583/ijpsrr.2021.v70i01.008

\section{INTRODUCTION}

$\mathrm{H}$ ealth Technology Assessment (HTA) is "a multidisciplinary process to evaluate the social, economic, organizational and ethical issues of a health intervention or health technology". The main goal of an HTA is to support health care decisions, to serve policymaking through objective information, and to support the decision-makers in making good decisions to keep the health care system accessible, and of the highest quality possiblei. In the area of orphan medicinal products (OMPs), access to the national markets seems to be difficult and inequal for many European countries ii.
The European Medicines Agency (EMA) defines rare diseases (RDs) as life-threatening or chronic diseases, which affect fewer than 5 in 10,000 people within the European Union. According to EMA, there are 25 to 30 million cases of rare diseases in Europe alone $\mathrm{e}^{\mathrm{iii}}$. Meanwhile, the number of rare diseases for which there is no treatment currently available is estimated to be between 4,000 and 5,000 out of a total of up to 8,000 RDs worldwide ${ }^{\mathrm{iv}}$.

The medicinal products used for diagnosis, treatment, and prevention of RDs are called "orphan medicinal products (OMP) iv . Many aspects need to be considered in the context of national OMP reimbursement: the lack of existing treatment options due to rarity of the condition and equity of access to treatment among different population segments, as well as providing fair returns on investment for research-based entities, while facing the reality of budget constraints ${ }^{\vee}$.

The European Union applications for orphan designation are examined by the EMA's Committee for Orphan Medicinal Products (COMP)iii. The granting of marketing authorisation for a drug does not always mean that the 
drug will be available in all countries within the European Union. The marketing authorisation holder (MAH) must decide beforehand on its status within each country. The drug then undergoes the necessary procedures in each country to establish reimbursement conditions, and usually its price.

There are a lot of challenges for any country trying to improve the accessibility of patients with rare diseases to orphan drugs because of the unaffordable prices and increasing expenditure on OMPs. Furthermore, clinical evidence available at marketing authorisation (MA) and the level of confidence authorities have for this evidence might be not sufficient of what HTA agencies normally consider to be adequate. This is particularly relevant for rare diseases (RDs), because the higher prices may not be proportionate to the expected level of evidence regarding benefit. OMPs are often not considered a cost-effective use of resources under standard criteria; this has led to several exceptions in the way OMPs are appraised, such as considering the severity of disease or the availability of therapeutic alternatives ${ }^{v}$.

In low- and middle-income countries the public healthcare budget is lower and to reimburse OMPs is a great burden, however, it is of great importance that orphan drugs can be reimbursed so that these drugs are made available to the patients. Different authorities are making decisions for OMPs reimbursement and performed the HTA. Additionally, the practices of international price referencing and parallel trade ensure that these high prices are similar across all EU countries ${ }^{v}$.

The purpose of this research is to provide a short overview of the differences in access to and health technology assessment of OMPs in selected low- and middle-income countries in Europe and discuss these in terms of some challenges in the face of HTA comparing with high-income countries.

We wanted to determine whether low and middle-income countries in Europe like Bulgaria, Ukraine, Moldova, Georgia, Serbia, North Macedonia have established an HTA procedure in their country's for OMPs reimbursement, availability of guidelines for their evaluation, and to compare them with countries with the high-income economy.

\section{MATERIALS AND METHODS}

This is a retrospective, desktop study of already published official inquiries of national or international institutions, scientific publications, and reports from national governing bodies who regulate and monitor HTA in lowand middle-income economies in Europe, with further regards to HTA of orphan medicinal products.

The World Bank (WB) provided information regarding the economic status of each country in Europe ${ }^{\mathrm{vi}}$. The observed countries were selected as examples, according to WB classification in high income, low income, and upper- middle-income. Only European countries were selected with either similar economic or historic development or neighbouring ones.

The searched international databases were that of the European medicines agency (EMA) and World health organization (WHO)'. In our search, we evaluated information about the HTA process, legislation, and procedures from EMA and WHO with special emphasis on OMPsi, iv. The health in transition (HiT) countries profile updated during the last 5 years was reviewed ${ }^{\text {vi }}$. Governmental bodies and scientific publications were focused to search for information on topics like Rare diseases, Orphan drugs, Orphan medicinal products, Health Technology Assessment (HTA), low- and middleincome countries, high-income countries, and the names of the selected countries ${ }^{\mathrm{vii}}$.

\section{RESULTS}

\section{Countries characteristics and access to OMPs}

In the World Development Indicators database, all 189 WB member countries, plus 28 other economies are classified according to their income. As per the WB low-income economies are defined as those with a gross national income (GNI) per capita of $\$ 1,035$ or less in 2019 , where middle-income economies are those with a GNI per capita of $\$ 1,036$ - \$4,045; upper-middle-income economies are those with a GNI per capita between $\$ 4,046$ and $\$ 12,535$; high-income economies are those with a GNI per capita of

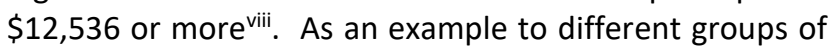
countries, we selected those pointed in Table 1.

Selected countries differ widely by population and income. Logically with the high income also increase the health care and pharmaceuticals per capita spending but not always. Surprisingly, Bulgaria spent more money per person on pharmaceuticals than the UK and in comparison, with the health care spending.

During 2000-2019 EMA approves 164 orphan medicines marketing applications $s^{i}$,i, ix. The highest is the number of OMPs available on the market in Germany ${ }^{x}$, followed by UK, Serbia, etc. According to NICE database in England are reimbursed 68, in Scotland 55, and in Wales 47 OMPs ${ }^{i i}$.

Ukraine reimburses 23 active substances for 7 diseases approved for state procurement based on the national drug program inclusion criteria, 12 diseases for children and adults, covering 65 INNs $^{x}$, ${ }^{x i}$. For Georgia and Moldova, no information about the available OMPs was found although some scientific conferences raise awareness on the topic. Of the 393 INNs included in the essential medicines list of WHO, 92 INNs are partially or fully reimbursed in Moldova mostly for children and pregnant women ${ }^{\text {xii. }}$. Access to life-saving medicines as insulin, analgesics for palliative care anti-HIV/AIDS, antituberculosis is granted through national programmes but OMPs are not separately mentioned as a country priority $^{\mathrm{xii}}{ }^{\mathrm{xiv}}$. 
Table 1: Characteristics of the observed countries in 2019

\begin{tabular}{|c|c|c|c|c|c|c|}
\hline Country & $\begin{array}{l}\text { Population } \\
\text { (mln) }\end{array}$ & $\begin{array}{l}\text { GDP per } \\
\text { capita } \\
\text { (US\$) }\end{array}$ & $\begin{array}{l}\text { Life } \\
\text { expectancy at } \\
\text { birth (yrs) }\end{array}$ & $\begin{array}{l}\text { Health } \\
\text { expenditures per } \\
\text { capita (US\$)-2018 }\end{array}$ & $\begin{array}{l}\text { Pharmaceutical } \\
\text { expenditures } \\
\text { per capita }\end{array}$ & $\begin{array}{l}n \text { of OMP } \\
\text { (INN) }\end{array}$ \\
\hline \multicolumn{7}{|c|}{ High-income-countries } \\
\hline $\begin{array}{l}\text { United } \\
\text { Kingdom }\end{array}$ & 66,5 & 42,330 & 81.26 & 4,315 & 497 & 68 (2019) \\
\hline Germany & 82,9 & 46,445 & 80.89 & 4,944 & 766 & $133(2019)$ \\
\hline \multicolumn{7}{|c|}{ Upper-middle-income } \\
\hline Bulgaria & 7 & 9,732 & 75 & 690 & 567 & $40(2012)$ \\
\hline Serbia & 7 & 7,379 & 75.9 & 617 & 158 & $59(2014)$ \\
\hline $\begin{array}{l}\text { North } \\
\text { Macedonia }\end{array}$ & 2,1 & 6,102 & 75.6 & 399 & n.a. & $52(2014)$ \\
\hline Georgia & 3,7 & 4,275 & 74.1 & 350 & 194 & n.a. \\
\hline \multicolumn{7}{|c|}{ Middle-income-countries } \\
\hline Moldova & 2,64 & 4,512 & 70.9 & 213 & 63 (2016) & n.a. \\
\hline Ukraine & 44 & 3,118 & 71.6 & 228 & 73 & 23 \\
\hline
\end{tabular}

\section{HTA policy}

In the United Kingdom, the HTA has the longest history in comparison with other selected countries. NICE is the institution that evaluates the cost-effectiveness of medicinal interventions and is involved in the designing of specific guidelines based on available evidence. In the UK, the purchasing decisions are made at a local level and purchasers are not obligated to include medicines or other interventions which have shown cost-effectiveness and vice versa $^{\mathrm{xv}}$. NICE has provided guidelines that are used across the whole country. Access to medicines could be also granted through Research \& Development Programmes (R\&D Program). NICE also has separated procedures for
OMPs and even orphan medicines threshold for reimbursement that is higher than the usual one of $\& 50,000$ per QALY.

In Germany, the Federal Ministry of Health sets the framework of the health system. The Statutory health insurance system (SHI reform), since 2000, established a federally funded HTA program with a database of relevant HTA results. The main purpose is to help and support the decision-making process in health care. They also established the Institute for Quality and Efficiency in Health Care (IQWIG). In contrast with UK the German agency evaluated the added benefit of the new technologies and for OMPs could apply the early access procedure ${ }^{\text {xvi }}$, viii.

Table 2: Availability and functioning of the national HTA institutions.

\begin{tabular}{|c|c|c|c|c|c|}
\hline Country & HTA body & $\begin{array}{l}\text { Year of } \\
\text { establishment }\end{array}$ & Guideline & Purpose of evaluation & $\begin{array}{l}\text { Separate } \\
\text { procedure for } \\
\text { OMP }\end{array}$ \\
\hline \multicolumn{6}{|c|}{ High-income countries } \\
\hline United Kingdom & NICE & 1999 & Yes & Reimbursement & Yes \\
\hline Germany & IQWIG & 2015 & Yes & Reimbursement & No \\
\hline \multicolumn{6}{|c|}{ Upper-middle-income } \\
\hline Bulgaria & NCPR & 2013 & Yes & Pricing and reimbursement & \\
\hline Serbia & $\begin{array}{l}\mathrm{MoH} \\
\text { committee }\end{array}$ & 2017 & No & Reimbursement & No \\
\hline North Macedonia & No & & & & \\
\hline Georgia & $\begin{array}{l}\text { State regulatory } \\
\text { agency for } \\
\text { medical } \\
\text { activities }\end{array}$ & 2015 & No & $\begin{array}{l}\text { Pricing, reimbursement, } \\
\text { budgeting, listing, guidelines }\end{array}$ & No \\
\hline \multicolumn{6}{|l|}{ Middle-income } \\
\hline Ukraine & $\begin{array}{l}\text { MoH } \\
\text { committee }\end{array}$ & $2016-2017$ & Yes & Pricing and reimbursement & No \\
\hline Moldova & No such & & No & n.a. & n.a. \\
\hline
\end{tabular}


Bulgaria had a special HTA commission established in NCPHA (National Centre of Public Health and Analyses). The commission has 13 members all part of the national health legislation system - MOH, the NHIF, the National Council on Prices and Reimbursement of Medicinal Products (NCPRMP), the Bulgarian Drug Agency (BDA), and the NCPHA. In 2017 the HTA process was moved to the National council on prices and reimbursement and gathered simultaneously with the process of pricing and decision making on reimbursement ${ }^{\text {xviii, }}$,ix. The decision must be applied for medicines that belong to a new "international proprietary name" or enlargement of the therapeutic indications. MAH applies for a drug to be included in the positive drug list (PDL) and provides a set of documents that are based on the comprehensive methodology outlined in the HTA Ordinance. The documents are assessed by experts appointed by the commission in collaboration with NHIF. The companies have to agree on discounts with NHIF before the listing of the new INN. The therapeutic effect of such medicines might become a subject of further monitoring and reimbursement must be renewed every 3 years after the medicine's inclusion in the PDL. The NCPR issued a guideline for HTA dossier structure and evaluation with a special chapter for medicines with unmet health needs.

There are no separate procedures for OMPs evaluation and reimbursement status granting, Serbia has an HTA commission established by the Ministry of Health with 5year mandates of the members of the HTA committee ${ }^{\mathrm{xx}}$, $\mathrm{xxi}$. They are health experts who have made a significant contribution to the development of certain fields of medicine, dentistry, pharmacy, the application, and the development of health technologies, or in the performance of health care services. Even though in 2003, the Ministry of Health acknowledged the need of developing more transparent criteria in the decision-making process regarding the introduction of the new innovative medicinal products or technologies, they still do not use the HTA, at least not in a systematic way using criteria such as efficacy and cost-effectiveness. In 2019, several articles of the Health Care Law indicate an obligation to apply HTA. Instead, the scope of work of the HTA commission is mostly related to the analysis of investment needs and covers the capital investments all around the country. It usually deals with problems associated with planning health care services and systems, rather than implementing technology assessments. There appear to be no clear procedures with objective and verifiable criteria related to the effectiveness, cost-effectiveness, or budget impact, in the process of listing medical devices or health care services at the National Health Insurance Fund (NHIF) nor the Ministry of Health. Furthermore, Serbia lacks a transparent and comprehensive system for assessing the benefit of health care investments and determining how to pay for them, including the OMPs ${ }^{\text {xviii }}$,

According to (WHO) Georgia and North Macedonia do not use HTA. Georgia considers the need of implementing assessments that are used in other countries. Meanwhile, North Macedonia does not use HTA for deciding which are the most cost-effective services to be included or which services to exclude ${ }^{\mathrm{xii}}$, xxii.

Since 2015 in Ukraine the health care system is experienced dynamic reform. A legislation framework has been adopted that regulates pharmaceutical pricing and reimbursement policies, the introduction of health technology assessment (HTA), etc. The first legislation on HTA was implemented in 2016-2017 and planned to be updated in 2019. For the first time in Ukraine, a country-specific HTA guideline was developed based on the literature review of international HTA submission guidelines. Since now there is no separate guideline and procedure for OMPs evaluation ${ }^{\text {xiii. }}$.

\section{DISCUSSION}

According to our research, there seems to be a connection between the economic status of a country and the development of HTA, where less developed economies appear to have less developed HTA policies. For example, the UK has a bigger budget for funding more programs related to medicines, surgical devices, etc. than North Macedonia. This appears to be in connection with the budget available for the healthcare system in general. In the Republic of North Macedonia, the term "rare diseases" is not defined explicitly in any law, which means that they are not highlighted to the healthcare system due to lack of definition, which also could mean that this reflects on the treatment and management of the diseases ${ }^{x x i v}$. Similarly, it appears that countries that have HTA policies set in place present a higher number of positive outcomes for decisions on the reimbursement of orphan medicines for rare diseases $^{\mathrm{xxv}}$.

Bulgaria became part of the European Union in 2007. Since then, the country's legislation is synchronized with the regulations set and governed by the European Union, and as per Kamusheva et al., Bulgaria has made some progress

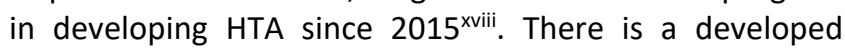
pharmacoeconomic and HTA guideline, and this guideline give the possibility of making the best possible scientific decisions with regards to reimbursement of medicinal products, and even more so with regards to OMPs. However, the guideline needs to be improved and developed in the future. Some problems such as lack of mechanisms for gathering sufficient data from real-world studies, the periodic legislative changes, and the lack of enough experts in the area could be highlighted. According to Kamusheva et al., there will be a guarantee for collecting more available and reliable evidence for effectiveness and cost-effectiveness if reassessment of reimbursement after their inclusion in Bulgaria's PDLs is performed. Collaboration with other European countries could be useful to find the best solutions for the reimbursement practice of OMPs to see if the new medicine brings additional benefits for patients with rare decease with no available alternative.

Serbia, a country that is not part of the EU, and is currently in the middle of investing a lot of resources in improving the efficiency and quality of their Health System ${ }^{\mathrm{xxi}}$. A part of 
their project is to improve access to medicines, strengthen HTA capacity, and improve medical equipment maintenance systems. They also want to develop new relationships with other HTA organizations, to make some changes and amendments to regulations and laws for improving HTA. As a country that wants to be a part of the $\mathrm{EU}$, these steps are in the right direction in making their health system corresponding to all the European directives. Considering this, the main difference between Bulgaria and Serbia is that Bulgaria is already using the HTA when new medicine needs to be included in PDL ${ }^{x \times v i}$. However, Serbia is now making reforms to start using it on a daily basis. According to in Serbia, the general criteria for placing an orphan drug 13 in their "Rare Decease Drug" list is to have pharmacotherapeutic justification, pharmacoeconomic justification, and funding provided by the Financial Plan of the Republic Fund. The Ministry of Health established a fund for rare metabolic diseases. Unfortunately, there are no criteria that specify which drug should be placed on the list. The management of resources coming from this Special fund is limited just on the clinical decision of choosing the most appropriate patient that will benefit the most from given medicine.

On the other hand, North Macedonia does not have an implemented HTA agency. Several documents have called for the need of implementing HTA, but it has yet to be accepted $^{x x v i i}$. Although both Serbia and North Macedonia are countries that are not part of the EU, Serbia is making a lot of reforms, investing a lot of money, and improve it's laws to work systematically and build upon the field of HTA whereas, North Macedonia needs to work on establishing an HTA body as a whole.

As far as we can see, the implementation of HTA in each country is uneven. One way to make more efficient and stronger HTA procedures is to improve the training of HTA specialists. An interesting approach to the implementation of HTA across Europe would be to look at how this is introduced at the academic level. Our research found that according to WHO, 13 European countries that have implemented HTA academic programs, and only several offer Master's programs - one of them being Bulgariaxxiii.

Meanwhile, Bulgaria, the UK, and Germany are all part of the European Union, where all three countries have HTA guidelines implemented in their health legislation. According to Malinovski et al., in Bulgaria, the National Council of Pricing and Reimbursement is the one to perform the procedure of HTA evaluation, pricing, and inclusion into the $P D L^{\text {ix }}$. Orphan drugs to be reimbursed do not necessarily need to show cost-effectiveness. Bulgarian regulation on HTA requires for the applying products to already have positive HTA evaluation in UK, or France, or Germany. This indicates that the Bulgarian regulation over its own HTA is not entirely independent from other, and higher-, income countries within the EUxviii.

On the other hand, according to Perleth et al., until 2009 in Germany there was no international standardized methodology for HTA available, for example, ethical, social, and legal aspects are not discussed in all cases ${ }^{\mathrm{xvi}}$. Furthermore, there were private actors on the HTA market and therefore, a risk for HTA to be influenced by industry is possible. However, our findings imply that some standards of reporting HTA reports should be established, for example, declaration of possible conflicts of interest. Although HTA has steadily gained importance in the public healthcare system, criticisms revolve around its bureaucratic nature. For some patient advocacy groups, HTA imposes as just another way to say "no" or to delay decisions. It will be of crucial importance for the future of HTA in Germany to actively involve patient groups and the media to gain acceptance for HTA-based decisions.

The United Kingdom, as per Drummond et al., is well known to show a strong interest in evidence health care, however, this interest is linked to the need of the National Health Services (NHS) ${ }^{x}$. After the creation of R\&D Program more money was invested into HTA with the most important purpose - to improve health care. As per Woolf et al, this resulted to create a knowledge-based health service with a strong research infrastructure. HTA is the largest and most developed of the programs within the strategy. It has a formal system for setting assessment priorities involving consultation within the NHS, and a National Co-ordinating Centre for Health Technology Assessment. The HTA program has public participation. The United Kingdom has made a major commitment to HTA and to seeking effective means of reviewing and distributing evidence. The UK's success story in the implementation of HTA implies that perhaps getting the public involved may improve confidence in the HTA program. This confidence can be improved also with the education of more specialists, just like in Ukraine and Bulgaria to perform more adequate and transparent $\mathrm{HTA}^{\mathrm{xxix}, \mathrm{xxx}}$.

However, if we were to approach HTA in terms of public participation, then this may once again present a challenge to the implementation of HTA of OMPs due to the limited number of participants available for clinical trials of ODs for rare diseases. In the UK it is estimated that 3.5 million people will be affected by a rare disease at some point in their lives and hence for the UK this may seem like a lot of patients have access to treatment, sometimes this is just an exception rather than a rule.23 Public participation is limited in each country. According to worldometers.info Bulgaria has a population of around 7 million. In a country with a low-income economy and low population, public participation in HTA is a major challenge both for clinical trials and patient organizations. Perhaps work for future studies could concentrate on whether public participation and awareness could improve HTA.

Our hypothesis was to review the differences in health technology assessment criteria for low- and middle-income countries in Europe and assess these in terms of any challenges in the face of HTA of orphan medicines. After we made the comparison between low- and middle- income countries then we decided to observe them and to compare them with countries with the high-income economy. We 
also wanted to see if all countries are facing the same challenges. Evidently, the HTA is in its development stage not only in middle and upper-middle bust also in highincome countries but health care spending affects positively its development as is the case of Germany.

In contrast with other international comparisons, this study provides and information about the countries that were not explored before like Georgia, and Moldova.

One major limitation for our study proved to be in the gathering of sufficient data for lower-income countries in Europe. Unfortunately, for a lot of the mentioned countries, there was no available data or it was old and out of date. The same was with information regarding orphan drugs regulation for these countries and rare diseases.

\section{CONCLUSION}

Even though that the high-income countries have more developed HTA guidelines and stronger and more secure health systems, all the countries mentioned in this work are facing similar challenges. The main difference is that these challenges are of different sizes. All the countries have limited budgets that have to be specifically spent for OMPs. Countries with less-developed HTA should take all the knowledge for good practices from countries like the United Kingdom for a more rigid framework. On the other hand, the adoption of public health plans with support from the World Bank, WHO, and the EU as adopted by Serbia and other comparable countries, represent model examples to be shared in greater depth from all the low-income countries. We also came to a recommendation that good practice is a country to have training programs for specialists in HTA, as this will improve the knowledge in professionals in the health care system.

Source of Support: The author(s) received no financial support for the research, authorship, and/or publication of this article.

Conflict of Interest: The author(s) declared no potential conflicts of interest with respect to the research, authorship, and/or publication of this article.

For any question relates to this article, please reach us at: editor@globalresearchonline.net

New manuscripts for publication can be submitted at: submit@globalresearchonline.net and submit_ijpsrr@rediffmail.com

\section{REFERENCES}

1. 'WHO. Health technology assessment. 2021. Available from: https://www.who.int/medical_devices/assessment/en/ [Cited 202114 January ]

2. ii Czech M, Baran-Kooiker A, Atikeler K, Demirtshyan M, Gaitova K, Holownia-Voloskova M, Turcu-Stiolica A, Kooiker C, Piniazhko O, Konstandyan N, Zalis'ka O, Sykut-Cegielska J. A Review of Rare Disease Policies and Orphan Drug Reimbursement Systems in 12 Eurasian Countries. Front Public Health. 2020 Jan 28;7:416. doi: 10.3389/fpubh.2019.00416. PMID: 32117845; PMCID: PMC6997877.

3. iii European Medicines Agency. Development of medicines for rare diseases. 2021. Available from: https://www.ema.europa.eu/en/news/development-medicines-rare-diseases [Cited 202116 January].

4. iv Szegedi M, Zelei T, Arickx F, Bucsics A, Cohn-Zanchetta E, Fürst J, Kamusheva M, Kawalec P, Petrova G, Slaby J, Stawowczyk E, Vocelka M, Zechmeister-Koss I, Kaló Z, Molnár MJ. The European challenges of funding orphan medicinal products. Orphanet J Rare Dis. 2018 Nov 6;13(1):184. doi: 10.1186/s13023-018-0927-y. PMID: 30396361; PMCID: PMC6219168.

5. ${ }^{\vee}$ Tordrup D, Tzouma V, Kanavos P, (2014) Orphan drug considerations in Health Technology Assessment ineight European countries. Rare Diseases and Orphan Drugs: An International Journal of Public Health, 1 (3). pp. 86-97.

6. vi Full list of country HiTs profiles. Euro.who.int. 2021 Available from: https://www.euro.who.int/en/aboutus/partners/observatory/publications/health-system-reviews-hits/full-list-of-country-hits [Cited 202113 January].

7. vii World Bank Group - International Development, Poverty, \& Sustainability. World Bank. 2021 Available from: https://www.worldbank.org/ [Cited 202114 January].

8. viii World Bank Country and Lending Groups - World Bank Data Help Desk. Datahelpdesk.worldbank.org. 2021 Available from: https://datahelpdesk.worldbank.org/knowledgebase/articles/906519-world-bank-country-andlending-groups [Cited 202115 January].

9. ix Malinowski KP, Kawalec P, Trąbka W, Czech M, Petrova G, Manova M, Savova A, Draganić P, Vostalová L, Slabý J, Männik A, Márky K, Rugaja Z, Gulbinovic J, Tesar T and Paveliu MS. Reimbursement Legislations and Decision Making for Orphan Drugs in Central and Eastern European Countries. Front. Pharmacol. 2019; 10:487. doi: 10.3389/fphar.2019.00487 PMID: 31139080.

10. ${ }^{x}$ http://www.apteka.ua/article/383101 (Cited 2019 September 18). 
11. ${ }^{x i}$ https://zakon.rada.gov.ua/laws/show/255-2019-\%D0\%BF (Cited 2019 September 18).

12. xii WHO. Current status of health technology assessment in the Balkan region. Apps.who.int. 2020. Available from: https://apps.who.int/iris/bitstream/handle/10665/336228/WHO-EURO-2020-1303-41053-55733-eng.pdf [Cited 202113 January].

13. xiiisautenkova N., A. Ferrario, G. Bolokhovets, P. Kanavos. Availability and affordability of medicines and assessment of quality systems for prescription of medicines in the Republic of Moldova. Health Policy Paper Series No. 6, WHO, Copenhagen, 2012).

14. ${ }^{x i v}$ Georgia HiT (2017). euro.who.int. 2017. Available from: https://www.euro.who.int/en/aboutus/partners/observatory/publications/health-system-reviews-hits/full-list-of-country-hits/georgia-hit-2017 [Cited 202114 January].

15. ${ }^{x}$ Drummond M, Banta D. Health technology assessment in the United Kingdom. Int J Technol Assess Health Care. 2009 Jul;25 Suppl 1:178-81. doi: 10.1017/S0266462309090618. Epub 2009 Jun 16. PMID: 19527538.

16. xviperleth M, Gibis B, Göhlen B. A short history of health technology assessment in Germany. Int J Technol Assess Health Care. 2009 Jul;25 Suppl 1:112-9. doi: 10.1017/S0266462309090515. Epub 2009 Jun 8. PMID: 19500440.

17. xvii Perleth M, Gibis B, Göhlen B. A short history of health technology assessment in Germany. Int J Technol Assess Health Care. 2009 Jul;25 Suppl 1:112-9. doi: 10.1017/S0266462309090515. Epub 2009 Jun 8. PMID: 19500440.

18. xviii Kamusheva M, Manova M, Savova AT, Petrova GI, Mitov K, Harsányi A, Kaló Z, Márky K, Kawalec P, Angelovska B, Lakić D, Tesar T, Draganic P, Geitona M, Hatzikou M, Paveliu MS and Männik A (2018) Comparative Analysis of Legislative Requirements About Patients' Access to Biotechnological Drugs for Rare Diseases in Central and Eastern European Countries. Front. Pharmacol. 9:795. doi: 10.3389/fphar.2018.00795

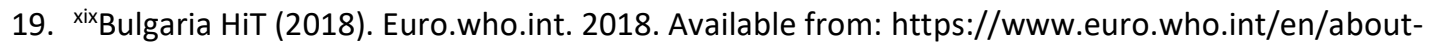
us/partners/observatory/publications/health-system-reviews-hits/full-list-of-country-hits/bulgaria-hit-2018 [Cited 202116 January].

20. ${ }^{x \times}$ Serbia (2019) HiT. Euro.who.int. 2019. Available from: https://www.euro.who.int/en/aboutus/partners/observatory/publications/health-system-reviews-hits/full-list-of-country-hits/serbia-2019-hit [Cited 202114 January].

21. ${ }^{x \times i}$ Atanasijevic D. RARE DISEASES MANAGEMENT IN SERBIA. Ispor.org. 2021. Available from: https://www.ispor.org/docs/default-source/presentations/93544pdf.pdf?sfvrsn=745ab712_0 [Cited 202117 January].

22. ${ }^{x x i i T h e ~ f o r m e r ~ Y u g o s l a v ~ R e p u b l i c ~ o f ~ M a c e d o n i a ~ H i T ~(2017) . ~ E u r o . w h o . i n t . ~} 2017$ Available from: https://www.euro.who.int/en/about-us/partners/observatory/publications/health-system-reviews-hits/full-list-ofcountry-hits/the-former-yugoslav-republic-of-macedonia-hit-2017 [Cited 202114 January].

23. xxiii Kotvitska AA, Nemchenko AS, Nazarkina VN (2020) The relevance of training specialists in the Health Technology Assessment in the world and Ukraine. Pharmacia 67(4): 295 301. https://doi.org/10.3897/pharmacia.67.e54777.

24. ${ }^{x x i v}$ RD-action.eu. 2017. Available from: http://www.rd-action.eu/wp-content/uploads/2018/03/Macedonia RDACTION-EUROPLAN-Workshop NARDM.pdf, [Cited 202117 January]

25. ${ }^{x \times v}$ Gammie T, Lu CY, Babar ZU. Access to Orphan Drugs: A Comprehensive Review of Legislations, Regulations and Policies in 35 Countries. PLoS One. 2015 Oct 9;10(10):e0140002. doi: 10.1371/journal.pone.0140002. PMID: 26451948; PMCID: PMC4599885.

26. ${ }^{x x v i K r a j n o v i c ́ ~ D, ~ A r s i c ́ ~ J, ~ T a s i c ́ ~ L, ~ P e t r o v a ~ G, ~ M i l i j i c ́ ~ S . ~ D o s t u p n o s t ~ l e k o v a ~ z a ~ r e t k e ~ b o l e s t i ~-~ k o m p a r a t i v n a ~ a n a l i z a ~}$ legislativnih zahteva između Srbije, Hrvatske i Makedonije. Acta medica Medianae. 2018;57(4):43-51

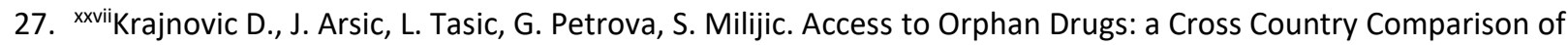
Legislative Approach among Serbia, Croatia and Macedonia. Acta Medica Medianae 2018; 57 (4); DOI: 10.5633/amm.2018.0406.

28. xxviii Chan AYL, Chan VKY, Olsson S, Fan M, Jit M, Gong M, Zhang S, Ge M, Pathadka S, Chung CCY, Chung BHY, Chui CSL, Chan EW, Wong GHY, Lum TY, Wong ICK, Ip P, Li X. Access and Unmet Needs of Orphan Drugs in 194 Countries and 6 Areas: A Global Policy Review With Content Analysis. Value Health. 2020 Dec;23(12):1580-1591. doi: 10.1016/j.jval.2020.06.020. Epub 2020 Oct 31. PMID: 33248513.

29. ${ }^{x x i x}$ Woolf S, Henshall C. Health technology assessment in the United Kingdom [Internet]. PubMed. 2000. Available from: https://pubmed.ncbi.nlm.nih.gov [Cited 2021 January 21].

30. ${ }^{x x}$ UK Strategy for Rare Diseases. Rare Disease UK. 2021. Available from: https://www.raredisease.org.uk/ukstrategy-for-rare-diseases/ [Cited 202117 January]. 